\title{
Maternal alcohol consumption in the Norwegian Mother and Child Cohort Study (MoBa) - Research opportunities
}

\author{
Lisa A. DeRoo \\ Department of Global Public Health and Primary Care, University of Bergen, P.O. Box 7804, NO-5020 Bergen, Norway \\ E-mail: Lisa.De.Roo@igs.uib.no
}

\begin{abstract}
The Norwegian Mother and Child Cohort Study (MoBa) is a valuable resource for the study of the effects of maternal alcohol consumption. MoBa's strengths include a population-based sample of over 107,000 pregnancies, concurrent and retrospective assessment of maternal prenatal and postnatal alcohol consumption, and prospective follow-up for pregnancy and child outcomes. Direct questions were asked on the frequency, dose and timing of maternal alcohol consumption. Screening tools including the T-ACE and partial Rutgers Alcohol Problem Index were used to identify women at risk for drinking during pregnancy. Comprehensive information on potential confounders was collected including maternal medical history, reproductive history, smoking, and other substance use. The detailed alcohol data allow the differentiation between non-binge and binge-level drinking, important for studying different thresholds of exposure. The availability of maternal and infant DNA enables the study of genetic differences in alcohol metabolism. Besides conventional analyses, sibship studies of differentially exposed siblings can be conducted among the offspring of over 15,000 women who participated in the study for more than one pregnancy. Although there are low levels of social disadvantage in Norway (poverty increases the risk of harms from prenatal drinking), binge drinking is a common pattern of consumption and previous studies found that drinking alcohol during pregnancy is not uncommon. Here, I provide a brief review of prenatal alcohol literature and measurement issues, describe $\mathrm{MoBa}$ alcohol variables, and discuss how $\mathrm{MoBa}$ can contribute to maternal alcohol research within the context of Norway.
\end{abstract}

This is an open access article distributed under the Creative Commons Attribution Licence, which permits unrestricted use, distribution, and reproduction in any medium, provided the original work is properly cited.

The Norwegian Mother and Child Cohort Study (MoBa) (1) is a valuable resource for studying the effects of women's alcohol consumption during pregnancy. MoBa's strengths include a large, populationbased sample of over 107,000 pregnancies among over 90,000 women recruited in early pregnancy in 19992008 with prospective follow-up for pregnancy and infant outcomes and long-term follow-up for child health and behavioral outcomes. Detailed information on antenatal and postnatal maternal alcohol consumption was collected in questionnaires completed by mothers during and after the pregnancy. Other relevant maternal characteristics and exposures were collected including medical history, reproductive history, smoking, other substance use, stress, occupation, diet and partner's substance use. In addition, information on complications of pregnancy and delivery, birth outcomes, and diagnoses in the child is available through record linkage to the Medical Birth Registry of Norway (MBRN), a mandatory national registry for all pregnancies ending after week 12 (week 16 prior to 2002) (2). Follow up is on-going and there is the opportunity to examine longterm behavioral and health outcomes in the children. Over 15,000 women participated for more than one pregnancy so it is possible to examine alcohol exposures across pregnancies and outcomes among siblings. Blood samples from mothers and fathers and cord blood from newborn infants were collected for DNA extraction and analysis; thus, analy- ses of prenatal alcohol exposure can explore the role of alcohol-metabolism genes that influence the rate of alcohol metabolism and affect fetal exposure. The aim of this paper is to provide a brief review of the effects of prenatal alcohol consumption, describe the information on maternal alcohol consumption collected in $\mathrm{MoBa}$, and discuss ways in which MoBa can contribute to this area of research within the unique context of Norway.

\section{BACKGROUND}

It is well established that heavy maternal alcohol consumption is associated with physical and developmental defects in the child that can lead to lifelong disabilities (3). Collectively referred to as fetal alcohol spectrum disorders (FASDs) (4), the most serious is fetal alcohol syndrome (FAS), characterized by prenatal or postnatal growth retardation, central nervous system dysfunction, and distinctive facial features (4, 5). FASDs also include alcohol-related neurodevelopmental disorders characterized by abnormal brain development and cognitive or behavioral problems (6). Not all women who drink during pregnancy give birth to an effected child. Even among heavy drinkers, women living in poverty or disadvantaged conditions have the greatest risk of having a child with FASD (79). Maternal smoking, inadequate diet, stress, poor health, heavy caffeine consumption, and drug use may 
exacerbate the effects of alcohol but may also act as independent risk factors for negative outcomes (8).

Whereas there is strong scientific evidence that heavy maternal alcohol consumption is associated with fetal harm (10), there is considerable debate on the risks of lower-level prenatal alcohol consumption $(11,12)$. The evidence for "low to moderate" prenatal alcohol exposure is mixed and overall unconvincing (13-17). The outcomes studied, including child behavioral problems and learning disorders, are nonspecific to alcohol and often subjectively evaluated through parent or teacher reports. It may be problematic to disentangle the effects of prenatal alcohol exposure from those of a negative early caregiving environment or other exposures (such as lead) that are also associated with cognitive deficits or behavioral problems (18). In some populations, moderate drinkers have higher education, higher income, better mental health, and stronger social networks than alcohol abstainers or heavy drinkers $(19,20)$, factors that may also be associated with good parenting and positive child outcomes. Some of these attributes are not easily captured by available socio-demographic variables, and it has been suggested that residual confounding could obscure the detrimental effects of lower-level prenatal alcohol exposure or bias results in the opposite direction $(17,21)$. Besides the possibility of biases and confounding, methodological weaknesses of these studies include small sample size and inadequate statistical power, lack of an unexposed referent group, and inadequate alcohol measures (lacking timing or pattern) (17).

The classification of maternal alcohol consumption has varied considerably across studies, and the definition of low and moderate drinking has been inconsistent. The peak blood alcohol concentration (BAC) is thought to be the most important determinant of alcohol-related fetal harm $(22,23)$ and is a critical factor in fetal brain injury (24). Peak BAC is a function of the amount of alcohol consumed, time spent drinking, blood volume, and the rate of alcohol metabolism. In pregnancy, alcohol diffuses across the placenta, reaching concentrations in the fetal circulation similar to that in the mother's (25). Binge drinking, usually defined as drinking 5 or more drinks per sitting (26) (sometimes 4 or more for women) (27), results in higher peak BACs than drinking fewer drinks over more occasions. Due to the relatively constant rate of alcohol metabolism, the body takes longer to clear the alcohol with binge drinking, resulting in prolonged fetal alcohol exposure (24). Many studies have assessed maternal drinking using the average number of drinks consumed per week but this measure obscures the amount consumed per occasion, which is the best proxy for peak BAC (23). For example, "moderate" consumption of 7-14 drinks per week pools together women drinking as low as one drink per day with those having up to three binge drinking episodes per week. Studies that do not distinguish between non- binge and binge drinking are difficult to interpret in terms of low to moderate exposure because any increased risks may be due to the inclusion of heavy, binge-level drinking.

Genetic variation may also influence fetal exposure. Variants in the genes encoding alcohol dehydrogenase and aldehyde dehydrogenase, the main alcohol metabolism enzymes, produce enzymes with differing rates of metabolism that affect the time required for alcohol clearance (28). These genes are expressed in the placenta and fetal liver (29), suggesting that both fetal and maternal genes may play a role.

\section{The MoBa STUdy ALCOHOL VARIABLES}

MoBa's data collection methods, maternal alcohol questions, and longterm follow up make it a valuable resource for studying the effects of prenatal alcohol exposure on birth and child outcomes. Alcohol consumption during pregnancy is uncommon in most populations, but MoBa's large sample size of over 107,000 pregnancies allows the study of a range of alcohol exposures and includes a large group of alcohol abstainers that can serve as the referent group. Data on prenatal exposures were collected prospectively, before the pregnancy ended, which avoids the potential for recall bias. Two complementary approaches were used for the collection of alcohol information: direct questions on alcohol consumption and the use of screening tools. The T-ACE (Tolerance, Annoyed, Cut-Down, Eye-opener) screening tool was used to identify women with alcohol-related problems who were at risk for drinking during pregnancy (30) and five questions from the Rutgers Alcohol Problems Index (31) were used to estimate alcohol problems in the last year. Direct questions on alcohol intake are critical for establishing the amount, frequency, timing, and type of alcohol consumed and the pattern of drinking. Not all risk drinking occurs among people with alcohol problems, so direct questions can identify risk drinkers who would be missed by screening tools. However, direct questions on alcohol use can trigger denial and underreporting, particularly among problem drinkers. Proponents of screening tools suggest that indirect questions on drinking consequences can avoid these problems (32). The availability of data from both direct and indirect questions allows the examination of self-reported prenatal alcohol consumption while taking into account whether the woman had a history of problem drinking.

Information on the frequency of drinking alcohol, the usual number of units consumed per occasion, and the frequency of drinking 5 or more units per occasion was collected across several self-administered questionnaires for different time periods before, during and after the pregnancy (Table 1). Questions on alcohol were asked retrospectively for the three months prior to the pregnancy and concurrently for each of the three pregnancy trimesters. One unit of alcohol was defined 
Table 1. Collection of maternal alcohol information by questionnaire number and referent period, MoBa Cohort Study.

\begin{tabular}{|c|c|c|c|c|c|c|c|c|c|c|c|c|}
\hline & \multirow{2}{*}{$\begin{array}{l}\text { Lifetime/ } \\
\text { no time, } \\
\text { reference }\end{array}$} & \multirow[b]{2}{*}{ Past year } & \multirow{2}{*}{$\begin{array}{c}\begin{array}{c}\text { Month pre- } \\
\text { pregnancy }\end{array} \\
-3 \text { to } 0 \\
\end{array}$} & \multicolumn{3}{|c|}{ Month during pregnancy } & \multicolumn{6}{|c|}{ Month post-pregnancy } \\
\hline & & & & $1-3$ & $4-6$ & $6-9$ & $0-3$ & $4-6$ & 18 & 36 & 60 & 96 \\
\hline Ever consumed alcohol & Q1 & & & & & & & & & & & \\
\hline Usual type(s) consumed & Q1 & & & & & & & & & & & \\
\hline Frequency of consuming alcohol & & & $\begin{array}{l}\text { Q1 } \\
\text { Q3 }\end{array}$ & $\begin{array}{l}\text { Q1 } \\
\text { Q3 }\end{array}$ & Q3 & $\begin{array}{l}\text { Q3 } \\
\text { Q4 }\end{array}$ & Q4 & Q4 & Q5 & \multicolumn{2}{|r|}{ Q-Y5 } & Q-Y8 \\
\hline $\begin{array}{l}\text { Usual number of units consumed } \\
\text { per time }\end{array}$ & & & $\begin{array}{l}\text { Q1 } \\
\text { Q3 }\end{array}$ & $\begin{array}{l}\text { Q1 } \\
\text { Q3 }\end{array}$ & Q3 & $\begin{array}{l}\text { Q3 } \\
\text { Q4 }\end{array}$ & Q4 & Q4 & $\mathrm{Q} 5^{\mathrm{a}}$ & \multicolumn{3}{|c|}{$Q-5^{\mathrm{a}}$} \\
\hline Frequency of consuming $5+$ units & & & Q1 & Q1 & & & & & & & & \\
\hline per time & & & Q3 & Q3 & Q3 & Q3 & & & & & & \\
\hline T-ACE Screening Tool & Q1 & & & & & & & & & & & \\
\hline Rutgers Alcohol Problem Index ${ }^{\mathrm{b}}$ & & Q1 & & & & & & & & & & \\
\hline Changes in drinking habits & & & Q3 & Q3 & Q3 & Q3 & & & & & & \\
\hline AUDIT $^{\mathrm{c}}$ Screening Tool & & Q-Y8 & & & & & & & & & & \\
\hline
\end{tabular}

$\mathrm{Q}=$ questionnaire; $\mathrm{Y}=$ year

${ }^{a}$ Information collected separately for weekdays and weekends

${ }^{\mathrm{b}}$ Partial index: 5 of 18 questions used

${ }^{\mathrm{c}}$ Alcohol Use Disorders Identification Test

as $1.5 \mathrm{cl}$ of pure alcohol and definitions of drink equivalents were provided for different types of alcoholic beverages. The data collected allows for the important differentiation between non-binge and binge alcohol consumption, the further delineation of binge drinkers into periodic bingers and those who drank at binge levels continually (each time they drank), and the estimation of the number of binge drinking episodes. The ability to make these distinctions and quantify the extent of heavy drinking is essential for studying different thresholds of exposure.

Respondents tend to reveal greater consumption of alcohol in self-administered questionnaires than interviews (33), suggesting that MoBa's mode of data collection may have avoided underreporting of prenatal alcohol consumption. Most studies rely on maternal self-report because even when biomarkers are available, they usually provide no information on timing or dose, and are often meaningful only in conjunction with maternal report (34). A special feature of the MoBa Study is the availability of repeat measures of alcohol consumption for some of the time periods. See Table 1 for the overlap in data collection by referent time period and MoBa Study questionnaire number. For example, women were queried around the end of the first trimester about alcohol intake up to that point in the pregnancy and were later asked again retrospectively (in a subsequent questionnaire) about alcohol intake during the first trimester. Studies have shown that women tend to report greater prenatal alcohol intake retrospectively than concurrently (35-37) perhaps because it is easier to disclose socially sensitive beha- vior when it occurred in the past. Given that underreporting prenatal drinking is more likely than overreporting (35), one approach to using the repeated selfreports is to use the greatest amount of consumption reported for a particular period when reports differ across questionnaires.

The information on the timing of maternal alcohol consumption is important because it enables researchers to tailor the alcohol exposure to the most relevant period for the particular outcome under study. For example, the first trimester is the relevant exposure period for structural birth defects because organogenesis takes place during this time, whereas alcohol exposures throughout pregnancy could affect cognition and behavior because brain growth and development is ongoing (38). MoBa collected information on changes in drinking habits and the timing of such changes before and during pregnancy, which can be used to further refine exposure measurements. In additional to periconceptional and prenatal drinking, follow-up questionnaires collected 'snapshots' of women's alcohol consumption at various times after the pregnancy. The Alcohol Use Disorders Identification Test (AUDIT) that identifies harmful patterns of alcohol consumption was administered in the 8-year questionnaire. Heavy post-pregnancy maternal drinking and alcohol problems may be indicative of the early home environment and can be taken into account in the assessment of longterm child outcomes.

The characteristics of the MoBa Study data allow for some special study designs and analyses that can facilitate the interpretation of results and strengthen 
causal inference pertaining to prenatal alcohol exposure. The availability of parental and child DNA allows for the study of gene-environment interactions between alcohol metabolism gene variants and prenatal alcohol exposure that, if found, would support causal associations. For example, one would expect the fetus to be more vulnerable to the effects of prenatal alcohol exposure when the mother and/or infant have gene variants for slower alcohol metabolism (39). Sibship studies of differentially exposed siblings are possible due to the large number of women who participated in MoBa for more than one pregnancy. The sibship design provides tight control for familial factors (genetic and social) that are difficult to adjust for in conventional analyses (40). The utility of this design is illustrated in a Swedish study (41) that initially found an association between prenatal smoking and increased risk of low intellectual performance in male offspring in a conventional analysis, but the sibship analysis revealed no association, suggesting that residual confounding accounted for the association in the conventional analysis. The sibship study design requires a sufficient number of siblings who differ on exposure status, but when feasible, it is a powerful method for enhancing causal inference (40).

\section{THE CONTEXT OF NORWAY}

MoBa joins other large-scale pregnancy studies and birth cohorts that have examined maternal alcohol consumption including the Avon Longitudinal Study of Parents and Children, the Danish National Birth Cohort, the Generation R Study, the Western Australian Pregnancy Cohort Study, and the UK Millennium Cohort Study, but the particular political and social characteristics of Norway make it a distinctive setting for this research. Norway has low levels of social disadvantage and poverty, which would tend to decrease the risk of harms from prenatal alcohol exposure. However, binge drinking, which produces high BACs that can cause fetal harm, is a common pattern of alcohol consumption $(42,43)$. A wealthy, social-democratic nation, Norway has an elaborate social safety net, free education and universal health care. Relative income poverty is not absent (6.8\% in 2004), but is less common than in many other countries (44). Norway has strict policies governing the sale, serving, and use of alcoholic beverages, but social norms are permissive of heavy drinking and drunkenness (45). In general, alcohol consumption tends to be reserved for weekends and special occasions, with large quantities consumed per drinking session (46). In a population-based survey of 28-year old Norwegians, $46 \%$ of women reported "usually" drinking 5-6 units or more per sitting, with $4 \%$ reporting extremely high usual intake of 10 or more units per sitting; the most important factor predicting alcohol use was parental alcohol habits, with drinking practices seemingly transmitted from one generation to the next (47). Because of the acceptance of heavy drinking in Norway and the relatively high gender equality, there may be less social stigma for women to report alcohol use than in the United States and other settings.

The Norwegian Directorate of Health recommends that women abstain from drinking alcohol during pregnancy (48), but available evidence suggests that prenatal drinking is not uncommon. In a representative sample of pregnant women receiving routine ultrasound in Oslo in 2000-2001, 25\% of respondents overall and $20 \%$ of those with planned pregnancies reported at least one binge-drinking episode during early pregnancy (37). Characteristics associated with binge drinking in this sample included older maternal age and smoking but not income or education level. A survey sponsored by the Norwegian Health Directorate found that 1 in 4 pregnant women found it difficult to turn down alcohol at work parties or Friday beer gatherings, suggesting that some women feel pressure to partake in social drinking before they have announced their pregnancy publicly (48). The 1997 prevalence of FAS/FASD in Norway was estimated at 0.3 per 1,000 births based on a national survey, but an educational campaign for healthcare and social workers to identify and refer children with FAS/FASD yielded a higher estimate of 1.1 per 1000 in Hordaland County during 1999-2004 (49). For the 41 children identified with FAS or FASD as part of this campaign, prenatal alcohol exposure was likely high $-85 \%$ were in foster care, some placed immediately after birth because of the mother's drinking problem.

Although the MoBa Study had a target enrollment population of all women who gave birth in Norway, less than half of invited women enrolled in the study (1). The women who agreed to participate differ from the population of women giving birth in Norway in 2000-2006 on several characteristics generally associated with higher socioeconomic status (SES) - they were less likely to be young $(<25$ years), single, or smoke cigarettes, and more likely to be married or cohabitating, have higher education, and take multivitamin and folic acid supplements than women who did not enroll in the study (50). The un-representative sample does not necessarily impede the calculation of valid exposure-outcome estimates $(50,51)$, and the relatively homogeneous sample may even help avoid confounding by maternal factors to the extent that women are similar. However, MoBa mothers and their offspring may be a low-risk group for prenatal alcoholrelated harms overall and therefore findings concerning alcohol exposures in MoBa may not generalize to disadvantaged populations.

$\mathrm{MoBa}$ has the capacity to contribute well-designed, longterm studies of the effects of prenatal alcohol exposure, particularly for low to moderate consumption levels. This is important given the high percentage of alcohol-exposed pregnancies in Norway reported in previous studies and the likelihood that some women will drink alcohol before pregnancy recognition. Like 
many countries, Norway has adopted the precautionary principle in regard to its current alcohol policy, recommending that women completely abstain from drinking alcohol during pregnancy. While many believe this is the safest approach, others argue that policies should reflect research evidence and that overstating the risks of low levels of prenatal drinking could have unintended consequences such as eroding women's trust in medical advice or causing unneces- sary anxiety or social condemnation $(52,53)$. MoBa can contribute to the study of prenatal alcohol consumption by refining the understanding of the effects of different levels of alcohol exposure and exploring the roles of genetic variation and concurrent exposures. Such studies could advance scientific understanding of the etiology of pregnancy and child conditions and help provide empirical evidence to inform health policy.

\section{REFERENCES}

1. Magnus P, Irgens LM, Haug K, Nystad W, Skjaerven R, Stoltenberg C, et al. Cohort profile: the Norwegian Mother and Child Cohort Study (MoBa). Int J Epidemiol 2006; 35 (5): 1146-50.

2. Irgens LM. The Medical Birth Registry of Norway. Epidemiological research and surveillance throughout 30 years. Acta Obstet Gynecol Scand 2000; 79 (6): 435-9.

3. Streissguth AP, O'Malley K. Neuropsychiatric implications and long-term consequences of fetal alcohol spectrum disorders. Semin Clin Neuropsychiatry 2000; 5 (3): 177-90.

4. Warren KR, Hewitt BG, Thomas JD. Fetal alcohol spectrum disorders: research challenges and opportunities. Alcohol Res Health 2011; 34 (1): 4-14.

5. Rosett HL. A clinical perspective of the Fetal Alcohol Syndrome. Alcohol Clin Exp Res 1980; 4 (2): $119-22$.

6. Hoyme HE, May PA, Kalberg WO, Kodituwakku P, Gossage JP, Trujillo PM, et al. A practical clinical approach to diagnosis of fetal alcohol spectrum disorders: clarification of the 1996 institute of medicine criteria. Pediatrics 2005; 115 (1): 39-47.

7. Abel EL. An update on incidence of FAS: FAS is not an equal opportunity birth defect. Neurotoxicol Teratol 1995; 17 (4): 437-43.

8. Abel EL, Hannigan JH. Maternal risk factors in fetal alcohol syndrome: provocative and permissive influences. Neurotoxicol Teratol 1995; 17 (4): 445-62.

9. May PA, Gossage JP. Maternal risk factors for fetal alcohol spectrum disorders: not as simple as it might seem. Alcohol Res Health 2011; 34 (1): 15-26.

10. Abel EL. Fetal alcohol abuse syndrome. New York: Plenum Press, 1998. xi, 260 pp.

11. Nathanson V, Jayesinghe N, Roycroft G. Is it all right for women to drink small amounts of alcohol in pregnancy? No. BMJ 2007; 335 (7625): 857.

12. O'Brien P. Is it all right for women to drink small amounts of alcohol in pregnancy? Yes. BMJ 2007; 335 (7625): 856.

13. Henderson J, Gray R, Brocklehurst P. Systematic review of effects of low-moderate prenatal alcohol exposure on pregnancy outcome. BJOG 2007; 114 (3): 243-52.

14. Polygenis D, Wharton S, Malmberg C, Sherman N, Kennedy D, Koren G, et al. Moderate alcohol consumption during pregnancy and the incidence of fetal malformations: a meta-analysis. Neurotoxicol Teratol 1998; 20 (1): 61-7.

15. O'Keeffe LM, Greene RA, Kearney PM. The effect of moderate gestational alcohol consumption during pregnancy on speech and language outcomes in children: a systematic review. Syst Rev 2014; 3 (1).

16. Flak AL, Su S, Bertrand J, Denny CH, Kesmodel US, Cogswell ME. The association of mild, moderate, and binge prenatal alcohol exposure and child neuropsychological outcomes: a meta-analysis. Alcohol Clin Exp Res 2014; 38 (1): 214-26.

17. O'Leary CM, Bower C. Guidelines for pregnancy: what's an acceptable risk, and how is the evidence (finally) shaping up? Drug Alcohol Rev 2012; 31 (2): 170-83.

18. Coles CD. Discriminating the effects of prenatal alcohol exposure from other behavioral and learning disorders. Alcohol Res Health 2011; 34 (1): 42-50.

19. Peele S, Brodsky A. Exploring psychological benefits associated with moderate alcohol use: a necessary corrective to assessments of drinking outcomes? Drug Alcohol Depend 2000; 60 (3): 221-47.

20. Niclasen J. Drinking or not drinking in pregnancy: the multiplicity of confounding influences. Alcohol Alcohol 2014; 49 (3): 349-55.

21. Zuccolo L, Lewis SJ, Smith GD, Sayal K, Draper ES, Fraser R, et al. Prenatal alcohol exposure and offspring cognition and school performance. A 'Mendelian randomization' natural experiment. Int J Epidemiol 2013; 42 (5): 1358-70.

22. Schenker S, Becker HC, Randall CL, Phillips DK, Baskin GS, Henderson GI. Fetal alcohol syndrome: current status of pathogenesis. Alcohol Clin Exp Res 1990; 14 (5): 635-47.

23. Abel EL. Fetal alcohol syndrome: same old, same old. Addiction 2009; 104 (8): 1274-5; discussion 1279-80.

24. Maier SE, West JR. Drinking patterns and alcohol-related birth defects. Alcohol Res Health 2001; 25 (3): $168-$ 74. 
25. Nava-Ocampo AA, Velazquez-Armenta Y, Brien JF, Koren G. Elimination kinetics of ethanol in pregnant women. Reprod Toxicol 2004; 18 (4): 613-7.

26. Cahlahan D, Cisin IH, Crossley HM. American Drinking Practices. New Brunswick: Rutgers Center for Alcohol Studies, 1969.

27. Wechsler H, Dowdall GW, Davenport A, Rimm EB. A gender-specific measure of binge drinking among college students. Am J Public Health 1995; 85 (7): 982-5.

28. Edenberg HJ. The genetics of alcohol metabolism: role of alcohol dehydrogenase and aldehyde dehydrogenase variants. Alcohol Res Health 2007; 30 (1): 5-13.

29. Gemma S, Vichi S, Testai E. Metabolic and genetic factors contributing to alcohol induced effects and fetal alcohol syndrome. Neurosci Biobehav Rev 2007; 31 (2): 221-9.

30. Sokol RJ, Martier SS, Ager JW. The T-ACE questions: practical prenatal detection of risk-drinking. Am $J$ Obstet Gynecol 1989; 160 (4): 863-8; discussion 868-70.

31. White HR, Labouvie EW. Towards the assessment of adolescent problem drinking. J Stud Alcohol $1989 ; 50$ (1): $30-7$.

32. Russell M. New assessment tools for risk drinking during pregnancy. Alcohol Health Res World $1994 ; 18$ (1): 55-61.

33. Rogers SM, Miller HG, Turner CF. Effects of interview mode on bias in survey measurements of drug use: do respondent characteristics make a difference? Subst Use Misuse 1998; 33 (10): 2179-200.

34. Jacobson SW, Chiodo LM, Sokol RJ, Jacobson JL. Validity of maternal report of prenatal alcohol, cocaine, and smoking in relation to neurobehavioral outcome. Pediatrics 2002; 109 (5): 815-25.

35. Ernhart CB, Morrow-Tlucak M, Sokol RJ, Martier S. Underreporting of alcohol use in pregnancy. Alcohol Clin Exp Res 1988; 12 (4): 506-11.

36. Jacobson SW, Jacobson JL, Sokol RJ, Martier SS, Ager JW, Kaplan MG. Maternal recall of alcohol, cocaine, and marijuana use during pregnancy. Neurotoxicol Teratol 1991; 13 (5): 535-40.

37. Alvik A, Haldorsen T, Groholt B, Lindemann R. Alcohol consumption before and during pregnancy comparing concurrent and retrospective reports. Alcohol Clin Exp Res 2006; 30 (3): 510-5.

38. Coles C. Critical periods for prenatal alcohol exposure. Alcohol Health Res World 1994; 18 (1): $22-9$.

39. Boyles AL, DeRoo LA, Lie RT, Taylor JA, Jugessur A, Murray JC, et al. Maternal alcohol consumption, alcohol metabolism genes, and the risk of oral clefts: a population-based case-control study in Norway, 19962001. Am J Epidemiol 2010; 172 (8): 924-31.

40. Susser E, Eide MG, Begg M. Invited commentary: The use of sibship studies to detect familial confounding. Am J Epidemiol 2010; 172 (5): 537-9.

41. Lundberg F, Cnattingius S, D'Onofrio B, Altman D, Lambe M, Hultman C, et al. Maternal smoking during pregnancy and intellectual performance in young adult Swedish male offspring. Paediatr Perinat Epidemiol 2010; 24 (1): 79-87.

42. Brathen G, Brodtkorb E, Sand T, Helde G, Bovim G. Weekday distribution of alcohol consumption in Norway: influence on the occurrence of epileptic seizures and stroke? Eur J Neurol 2000; 7 (4): 413-21.

43. Makela P, Fonager K, Hibell B, Nordlund S, Sabroe S, Simpura J. Episodic heavy drinking in four Nordic countries: a comparative survey. Addiction 2001; 96 (11): 1575-88.

44. OECD. Income distribution and poverty - OECD. [cited 2014 June 20]. Available from: http://www.compareyourcountry.org/index.php?cr=oecd\&lg=en.

45. Nordlund S. Popular norms, alcohol policy and drinking behaviour. 2012. In: Alcohol Policy in Europe: Evidence from AMPHORA [Internet]. Brussels: Alcohol Public Health Alliance; [24-31]. Available from: http://amphoraproject.net/view.php?id_cont=45.

46. Makela P, Gmel G, Grittner U, Kuendig H, Kuntsche S, Bloomfield K, et al. Drinking patterns and their gender differences in Europe. Alcohol Alcohol Suppl 2006; 41 (1): i8-18.

47. Pedersen W, von Soest T. Socialization to binge drinking: a population-based, longitudinal study with emphasis on parental influences. Drug Alcohol Depend 2013; 133 (2): 587-92.

48. Helsedirektoratet. Gravid og alkohol [July 1, 2014]. Available from: https://helsenorge.no/gravid/gravid-ogalkohol.

49. Elgen I, Bruaroy S, Laegreid LM. Lack of recognition and complexity of foetal alcohol neuroimpairments. Acta Paediatr 2007; 96 (2): 237-41.

50. Nilsen RM, Vollset SE, Gjessing HK, Skjaerven R, Melve KK, Schreuder P, et al. Self-selection and bias in a large prospective pregnancy cohort in Norway. Paediatr Perinat Epidemiol 2009; 23 (6): 597-608.

51. Nohr EA, Frydenberg M, Henriksen TB, Olsen J. Does low participation in cohort studies induce bias? Epidemiology 2006; 17 (4): 413-8.

52. Gavaghan C. "You can't handle the truth"; medical paternalism and prenatal alcohol use. J Med Ethics 2009; 35 (5): 300-3.

53. Richardson SS, Daniels CR, Gillman MW, Golden J, Kukla R, Kuzawa C, et al. Society: Don't blame the mothers. Nature 2014; 512 (7513): 131-2. 